\title{
Anatomical and Developmental Patterns of Facilitative Glucose Transporter Gene Expression in the Rat Kidney
}

\author{
Edward Chin, Jian Zhou, and Carolyn Bondy \\ Developmental Endocrinology Branch, National Institute of Child Health and \\ Human Development, National Institutes of Health, Bethesda, Maryland 20892
}

\begin{abstract}
In situ hybridization was used to map cellular patterns of gene expression for facilitative glucose transporters (GTs) 1-5 in the developing and adult rat kidney. GT3 was not detected. GT1 mRNA was present in the proximal straight tubule (PST), distal nephron and collecting duct. GT2 mRNA was localized in both proximal convoluted and PST, while GT5 mRNA was detected only in the PST. GT4 mRNA and immunoreactivity were focally localized in the thick ascending limb of Henle's loop and were coexpressed with IGF-I. Thus, each of the four different isoforms demonstrated a distinct renal distribution, with GTs 1, 2, and 5 coexpressed in the PST. Renal GT1 and GT5 gene expression were unchanged throughout development, while GT2 was most abundant before weaning and GT4 was first detected after weaning. Only GT4 appeared to be hormonally regulated: It was decreased after hypophysectomy and increased after vasopressin treatment, but was not affected by 1 or $4 \mathrm{~d}$ of insulinopenic diabetes mellitus. The coexpression of GT4 and IGF-I in the thick ascending limb segment of the nephron suggests a novel autocrine/paracrine mechanism by which cells may control local fuel economy independently from that of the larger structure to which they belong and from the systemic hormonal milieu. (J. Clin. Invest. 1993. 91:18101815.) Key words: glucose metabolism • nephron • vasopressin • insulin-like growth factor $\bullet$ mRNA
\end{abstract}

\section{Introduction}

In recent years, five different facilitative glucose transporters ([GTs 1-5 $]^{1}$ named in order of their cloning) have been characterized (for recent reviews, see references 1-3). These integral membrane glycoproteins display significant sequence homology and appear to be members of a genetically related transporter family. The glucose transporter isoforms show different

Address correspondence to Dr. Edward Chin, Building 10/10N262, National Institutes of Health, Bethesda, MD 20892.

Received for publication 12 August 1992 and in revised form 18 November 1992.

1. Abbreviations used in this paper: dDAVP, 1 [desamino]-8-D-arginine vasopressin; E20, embryonic day 20; GT, glucose transporter; $\mathrm{Hx}$, hypophysectomized; IS/OM, inner stripe of the outer medulla; PCT, proximal convoluted tubule; PST, proximal straight tubule; TAL, thick ascending limb.

The Journal of Clinical Investigation, Inc.

Volume 91, April 1993, 1810-1815 affinities for glucose, different tissue-specific patterns of distribution and may be subject to differential hormonal regulation (for review, see reference 4 ). For example, the high affinity GT4 is preferentially expressed in fat and muscle and is regulated by insulin.

IGFs, like insulin, stimulate glucose uptake and glucose transporter gene expression (5-7). Since IGF-I mRNA is focally localized in the renal medullary thick ascending limb (TAL) (8), the nephron segment characterized by a unique dependence on oxidation of glucose $(9,10)$, we thought IGF-I might be involved in the regulation of local renal glucose metabolism. Seeking evidence of an association between renal IGF-I expression and specific local glucose transporter expression, we have used in situ hybridization and immunocytochemistry to examine cellular expression of GTs $1-5$ in the rat kidney.

\section{Methods}

Experimental animals: development, hypophysectomy, and growth hormone (GH) treatment. Sprague-Dawley rats (Taconic Farms, Germantown, NY) were used in protocols approved by the National Institute of Child Health and Human Development Animal Use Committee. Timed pregnant dams were anesthetized with carbon dioxide, and embryonic day 20 (E20) fetuses were removed by hysterotomy, and their kidneys were removed and frozen over dry ice. Kidneys were also obtained from male rats 5,16 , and $40 \mathrm{~d}$ after birth. Frozen sections were cut at a thickness of $10 \mu$, thaw mounted on poly-L-lysine-coated slides, and stored at $-70 \mathrm{C}$ until use. Female Sprague-Dawley rats hypophysectomized or sham operated at $20 \mathrm{~d}$ of age, were obtained from Taconic Farms. Hypophysectomized ( $\mathrm{Hx}$ ) rats demonstrating a weight gain $\leq 10 \%$ of that gained by sham-operated rats for the first 5 postoperative days were judged to have undergone successful pituitary ablation and were apportioned into groups receiving diluent or growth hormone beginning on the 6th $\mathrm{d}$ after surgery. Hx rats received $150 \mu \mathrm{g}$ growth hormone (NIDDK-rat GH-B-12, AFP-10478C; National Hormone and Pituitary Program, Baltimore, MD) intraperitoneally, or an equal volume of diluent twice a day. Rats were given water containing 5\% sucrose and rat chow ad libitum. Rats were killed in groups of three ( 1 sham + diluent, $1 \mathrm{Hx}+$ diluent, $1 \mathrm{Hx}+\mathrm{GH}$ ) after 1,2 , and $3 \mathrm{~d}$ of treatment, at 7, 8, and $9 \mathrm{~d}$ after surgery, respectively.

Saline, 1-[desamino]-8-D-arginine vasopressin (dDAVP) and streptozotocin treatments. The effects of saline, dDAVP and diabetes on renal GT gene expression were evaluated in male rats $(125-150 \mathrm{~g})$. One group $(n=4)$ was provided $3 \%$ saline to drink and the control group $(n=4)$ was given tap water. Both groups were killed after $3 \mathrm{~d}$. Other groups were given dDAVP (Rorer Pharmaceuticals, Fort Washington, PA), $4 \mathrm{mcg} / \mathrm{kg}$ i.p. $(n=4)$, or an equal volume of diluent $(n=4)$, and were killed $6 \mathrm{~h}$ after injection. Diabetes was induced with streptozotocin $100 \mathrm{mg} / \mathrm{kg}$ (Sigma Immunochemicals, St. Louis, MO) intravenously via a tail vein at $0900 \mathrm{~h}$ on day 0 after a $12-\mathrm{h}$ fast. Con- 

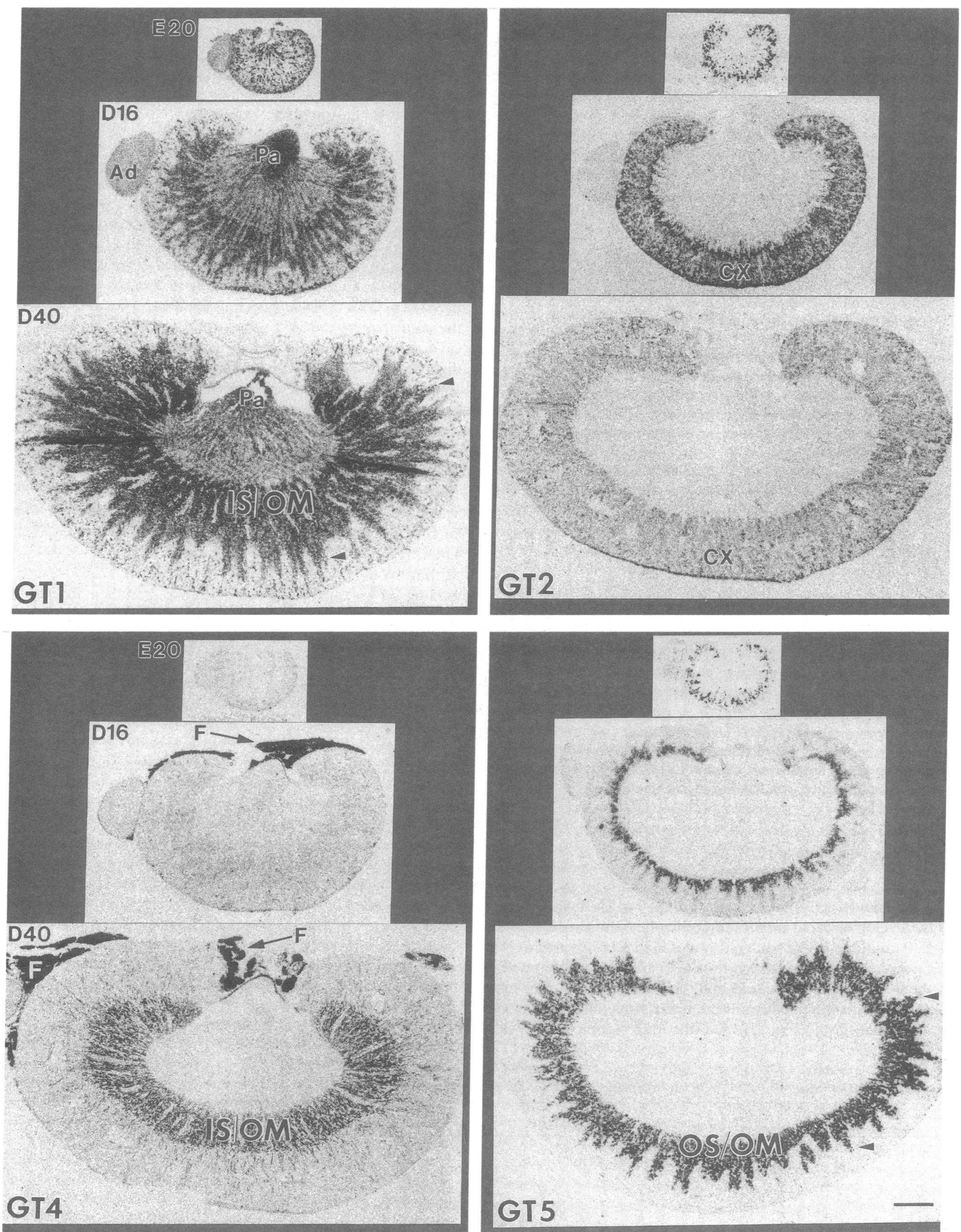

GT5

Figure 1. Renal GT1, GT2, GT4, and GT5 gene expression during postnatal development as shown by in situ hybridization. Film autoradiographs of serial sections from embryonic day $20(E 20)$, postnatal day $16,(D 16)$ and postnatal day $40(D 40)$ hybridized to the different cRNA probes are shown. The GT1 film was exposed for $7 \mathrm{~d}$. The GT2 and GT4 films were exposed for $10 \mathrm{~d}$, while the GT5 film was exposed for $5 \mathrm{~d}$. $A d$, adrenal; $F$, fat, $P a$, papilla; $I S / O M$; inner stripe of the outer medulla; $O S / O M$, outer stripe of the outer medulla; $C X$, cortex, arrowheads, medullary rays. Bar, $5.9 \mathrm{~mm}$. 
trols received an equal volume of diluent. Whole blood glucose was measured daily by reflectance photometer. Animals with blood glucose $>300 \mathrm{mg} / \mathrm{dl}$ were considered diabetic and were killed along with controls $1 \mathrm{~d}(n=4$ in each group) and $4 \mathrm{~d}$ (control, $n=3$; diabetic, $n=3$ ) after injection.

In situ hybridization and immunohistochemistry. The synthesis of ${ }^{35} \mathrm{~S}$-labeled cRNA probes and in situ hybridization protocol have been previously described (11). The cDNAs used for probe synthesis in the present study were the rat IGF-I (12), GT1 (13), GT2 (14), and GT4 (15) and a mouse GT3 (16) which have been previously described. A coding region fragment (corresponding to nucleotides 1-1578) from the rat GT5 clone (17) was subcloned into the EcoRI/Xbal sites of pGEM4Z so that T7 RNA polymerase was used for antisense and SP6 for sense transcription.

Quantification of renal mRNA levels from film autoradiographs was done as follows: Four anatomically matched sections from the left kidney of each animal were analyzed. All sections from a given experiment were prepared, hybridized, washed, exposed, and analyzed together. Results were quantified by computer-assisted densitometry as previously described (18). Unpaired, two-tailed $t$ tests were used to evaluate the significance of differences in mean densities among the $\mathrm{Hx}, \mathrm{GH}$-treated, dDAVP, saline-treated, and diabetic groups, and their respective control groups.

Immunohistochemistry was performed by a biotin-streptavidinhorseradish peroxidase method previously described (19). Fresh-frozen tissue was treated with Zamboni's fixative for $1 \mathrm{~h}$ then blocked with $3 \% \mathrm{H}_{2} \mathrm{O}_{2} / 3 \%$ methanol and avidin/biotin (Vector Laboratories, Burlingame, $\mathrm{CA}$ ). Sections were incubated with the primary antibody at a 1:20 dilution (a monoclonal antibody against the last 13 AAs of the carboxy terminal of GT4) at $4^{\circ} \mathrm{C}$ overnight then with biotinylated horse anti-mouse $\operatorname{IgG}(1: 100$, Vector) for $30 \mathrm{~min}$ at room temperature. Sections were then treated with an avidin-biotinylated-peroxidase complex (ABC Elite; Vector Laboratories) and a horseradish peroxidase-diaminobenzidine (Vector Laboratories). Sections were lightly counterstained with hematoxylin. When combined with in situ hybridization all solutions were made with diethyl pyrocarbonate (DEPC)treated water. $180 \mathrm{U} / \mathrm{ml}$ RNAsin (Promega, Madison, WI) and $0.04 \%$ diethyl pyrocarbonate (Fluka Chemie AG, Buchs, Switzerland) were added to the antibody, normal serum, and avidin-biotinylated-peroxidase complex. Chromogenic solution contained only RNAsin. Sections were incubated with hybridization buffer for $2 \mathrm{~h}$ at $55^{\circ} \mathrm{C}$ before hybridization.

\section{Results}

Developmental GT gene expression. GT1 mRNA was detected in developing renal tubules in both cortex and medulla of the E20 rat kidney. The adult pattern of GT1 gene expression was present by day 16 , at which time GT1 mRNA was detected in the inner and outer medulla and medullary rays, but was most abundant in the papilla and the inner stripe of the outer medulla (IS/OM) (Fig. 1). On the microscopic level, GT1
mRNA was localized in the epithelial cells of the proximal straight tubule (PST), thin limbs, the TAL of the loop of Henle, distal nephron, and collecting duct. GT2 mRNA was abundant in the cortex of the E20 kidney and levels declined through postnatal development until day 40 (Fig. 1). Microscopically, GT2 mRNA was localized in the epithelial cells of the proximal convoluted tubules (PCT) and PST. GT5 mRNA was detected in the cortex of the E20 rat kidney and the adult pattern of localization in the medullary rays and outer stripe of the outer medulla was seen by day 16 . Microscopically, GT5 mRNA was localized in proximal straight tubule epithelium. In contrast, GT4 mRNA was not detected in the kidney until day 16 when it was faintly discernible in the IS/OM (Fig. 1). By day 20, GT4 mRNA was more abundant (not shown) and the adult pattern of GT4 gene expression was seen by D40. GT4 mRNA was concentrated in the IS/OM and was also highly abundant in the perinephric fat. GT3 mRNA was not detected in the rat kidney. The different anatomical and developmental patterns of renal GT gene expression are summarized in Table I.

Cellular localization of Renal GT4. GT4 mRNA was focally localized in TALs that originate at the border between the inner and outer medulla (Fig. $2 A$ ). GT4 immunoreactivity was also focally localized in TALs in a pattern identical to that of GT4 mRNA (Fig. $2 B$ ). It was detected both in long loops entering the IS/OM to form TALs and in short loops that turn within the IS/OM to become TALs (Fig. $2 B$ ). Tubules containing GT4 were identified as TALs based on their absence of branching and brush borders, and presence of simple cuboidal epithelium (Fig. 2, B and C). GT4 immunoreactivity was diffusely present throughout TAL epithelial cells and did not appear to be concentrated at either the apical or basal surfaces. Intensely staining granules were also seen within the cell, suggesting the presence of GT4 immunoreactivity in small vesicles (Fig. $2 C$ ). Intense GT4 immunostaining was also present in the perinephric fat (Fig. $2 \mathrm{D}$ ).

Since we have previously demonstrated that IGF-I mRNA is focally localized in medullary TALs (8), we hypothesized that IGF-I and GT4 were coexpressed in the same nephron segment. Combined in situ hybridization and immunohistochemistry showed that IGF-I mRNA and GT4 immunoreactivity are colocalized in the same TAL cells (Fig. $2 E$ ).

Regulation of renal GT gene expression. The developmental regulation of renal GT4 gene expression led us to examine the effects of hypophysectomy and $\mathrm{GH}$ replacement on renal GT4 gene expression. Renal GT4 mRNA was significantly decreased by hypophysectomy and remained significantly decreased after 1, 2, and $3 \mathrm{~d}$ of $\mathrm{GH}$ replacement (Fig. $3 \mathrm{~A}$ ). GT1, GT2, and GT5 gene expression were not changed by $\mathrm{Hx}$ or GH

Table I. Distribution of Renal Glucose Transporter Gene Expression

\begin{tabular}{|c|c|c|c|c|c|c|c|c|}
\hline & G & PCT & PST & TL & TAL & DCT & CD & Developmental expression \\
\hline GT1 & - & - & + & + & + & + & + & E20 to maturity \\
\hline GT2 & - & + & + & - & - & - & - & Most abundant perinatally \\
\hline GT3 & - & - & - & - & - & - & - & Not detected at any stage \\
\hline GT4 & - & - & - & - & + & - & - & Not detected until renal maturation \\
\hline GT5 & - & - & + & - & - & - & - & E20 to maturity \\
\hline
\end{tabular}

G; glomerulus, TL, thin limb of the loop of Henle; DCT, distal convoluted tubule; CD, collecting duct. 

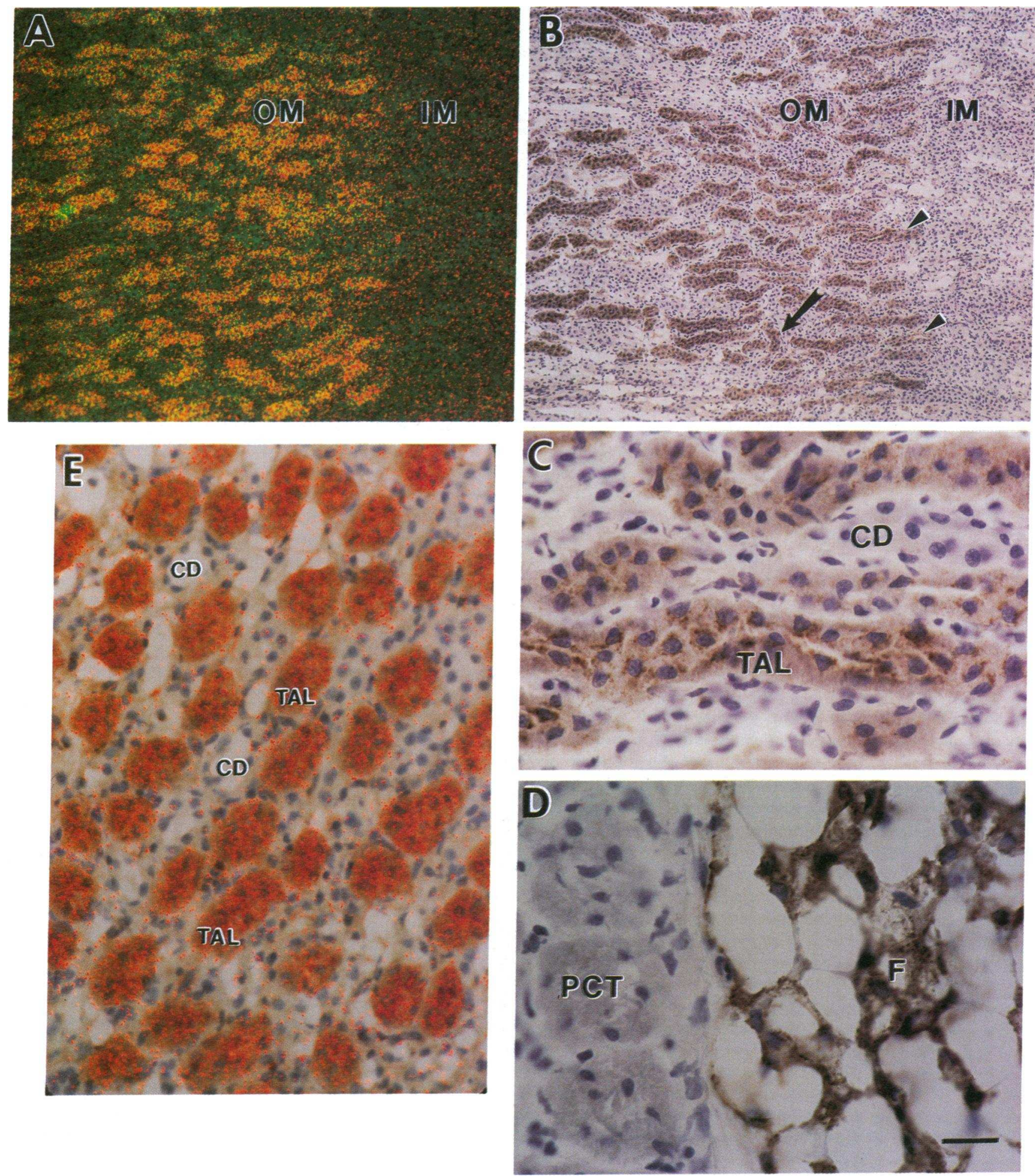

Figure 2. Cellular localization of renal GT4 mRNA and immunoreactivity. Colocalization with IGF-I gene expression. $(A)$ GT4 mRNA localization in TALs in a longitudinal section showing the border between the inner medulla $(I M)$ and outer medulla $(O M)$. This is a darkfield photomicrograph in which the hybridization signal appears as orange grains. $(B)$ GT4 immunoreactivity in TALs in a section sequential to that shown in $A$. Brown immunostaining is seen in the TALs of long loops (arrowheads) entering the outer medulla and in TALs of short loops (arrow) that turn within the outer medulla. $(C)$ GT4 immunoreactivity is diffusely localized in TAL epithelium. Immuno-negative thin limbs and collecting ducts $(C D)$ run along side the TALs. $(D)$ GT4 immunoreactivity in perinephric fat. Proximal convoluted tubules are seen in the nearby renal tissue. $(E)$ Colocalization of IGF-I mRNA and GT4 immunoreactivity in TALs in a tangential section through the inner stripe of the outer medulla. IGF-I mRNA hybridization signal appears as red grains and are detected in the same TALs as the brown immunostaining for GT4. Bar, $10 \mu \mathrm{m}(A$ and $B) ; 2.5 \mu \mathrm{m}(C$ and $D) ; 5 \mu \mathrm{m}(E)$. 
replacement (data not shown). Vasopressin secretion is also altered after $\mathrm{Hx}$ and so we examined the effect of activating endogenous vasopressin release by saline treatment and also the effect of dDAVP administration to normally hydrated rats. Saline treatment caused a significant increase in GT4 mRNA, and dDAVP caused an even more robust increase in GT4 mRNA that was apparent at $6 \mathrm{~h}$ after administration (Fig. 3 $B)$. GT1 gene expression was not changed with either treatment (data not shown). We also examined the effect of streptozotocin-induced diabetes mellitus and found that renal GT4 mRNA levels were not significantly changed at either $24 \mathrm{~h}$ or 4 $\mathrm{d}$ after the induction of diabetes mellitus (Fig. $3 \mathrm{~B}$ ).

\section{Discussion}

Renal functions in glucose metabolism include the transfer of glucose from the filtrate across epithelial cell membranes into the bloodstream, the de novo synthesis of glucose for release into the bloodstream, and the utilization of glucose in both glycolytic and oxidative pathways $(9,10,20)$. These different activities are compartmentalized in different segments of the nephron, as has been shown by the mapping of gluconeogenic and glycolytic enzymes to different segments (10). The present study indicates that facilitative glucose transporter gene expression is also segmentally compartmentalized.

The localization of GT1 mRNA in the proximal straight tubule, TAL, distal nephron, and collecting duct agrees with previous studies locating GT1 immunoreactivity in these same segments $(21,22)$. These segments also possess glycolytic enzymes which metabolize glucose to lactate, partly to satisfy energy requirements, but also to participate in complex free water clearance and ion transport pathways (10). Thus, renal epithelial GT1 expression appears to be linked to facilitation of glucose entry into glycolytic pathways. The glomerulus contains glycolytic enzymes (10), but neither GT1 nor any other GT mRNA was detected here. It is possible that very low levels of GT1 mRNA escaped detection, or that another transporter isoform is localized in the glomerulus.

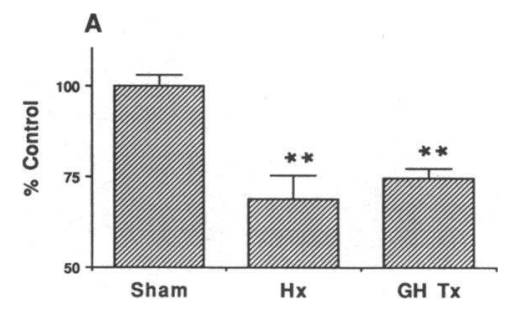

Figure 3. Regulation of renal GT4 gene expression. $(A)$ shows the effects of hypophysectomy $(H x)$ with and without GH replacement. Hx rats had similar decreased levels of renal GT4 mRNA at 7 , 8 , and $9 \mathrm{~d}$ postoperatively, as did the $\mathrm{Hx}$ rats that received $\mathrm{GH}$ re-

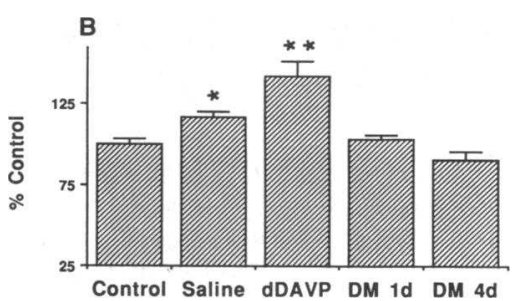
placement for 1,2 , and $3 \mathrm{~d}(7,8$, and $9 \mathrm{~d}$ postoperatively), hence the density values were pooled for each group. $(B)$ shows the effects of saline, dDAVP and streptozotocin-induced diabetes mellitus $(D M)$ on renal GT4 mRNA levels. Levels are expressed as a percent of control and each experimental group had its own control group. Results are given as means \pm SEM. ${ }^{*} P<0.05,{ }^{* *} P<0.005$.
Renal GT2 mRNA is localized to the proximal convoluted and proximal straight tubule. GT2 immunoreactivity has been reported in the proximal convoluted tubule but not in the proximal straight tubule $(21,23)$. Failure to detect GT2 immunoreactivity in the latter segment might be caused by an undetectable level of translation or a modified protein which escapes immunodetection. Proximal tubules use other substrates in preference to glucose for energy (10) and export glucose that is accumulated intracellularly as a result of reabsorption from the glomerular filtrate and/or gluconeogenesis $(20,24)$. Hence, the expression of the low affinity GT 2 by the proximal tubules is consistent with a role in the movement of glucose from tubular epithelium into peritubular vasculature. The high level of renal GT2 gene expression in the perinatal period may be related to the fact that the kidney alone seems to be responsible for gluconeogenesis during this time before expression of gluconeogenic enzymes by the liver (25).

This is the first study to describe the localization of GT5 in the kidney. Previous studies have demonstrated the presence of GT5 mRNA in the kidney by Northern blotting $(17,26)$ and GT5 immunoreactivity by Western blotting (27). Recent studies have suggested that in humans, GT5 may function primarily as a fructose transporter (28), but the rat isoform demonstrates significantly different transport properties and tissue distribution (17), and its role remains unclear. The present study has shown that the epithelial cells of the PST express at least three different facilitative hexose transporters; i.e., GT1, GT2, and GT5. Glucose is actively reabsorbed from the glomerular filtrate by a $\mathrm{Na}$-dependent glucose transporter, SGLT1, which has been localized in the apical brush border epithelium of both PCT and PST $(22,23)$. Immunocytochemical studies have shown that GT1 and GT2 are localized on the basolateral border of PST epithelium $(21,22)$. In the human intestine, GT5 immunoreactivity is localized in the epithelial brush border, suggesting that it transports hexoses from the lumen for systemic absorption (29). It will be important to determine whether GT5 is expressed on the apical or basolateral surface in the PST to better understand its role in the kidney.

This study is also the first to describe the renal localization of GT4. Previous studies have detected a weak GT4 mRNA signal in kidney homogenates, but there was concern that this might represent contamination of the samples by perinephric fat $(22,30-32)$. The present in situ hybridization and immunocytochemical analysis demonstrates that GT4 is indeed abundant in perinephric fat, but that it is also focally expressed in the renal tubular epithelium of the thick ascending limbs. The pattern of GT4 immunostaining is consistent with localization of the transporter on the highly convoluted basolateral membrane of this segment (33), as well as in cytoplasmic granules or vesicles. The timing of renal GT4 gene expression coincides with the ontogeny of urinary concentrating ability and vasopressin sensitivity (34), suggesting that GT4 is involved in the metabolic support of this specific function. The TAL has the highest level of $\mathrm{Na} / \mathrm{K}$ ATPase activity and the highest level of oxidative metabolism of any part of the nephron, and in contrast to other nephron segments, preferentially uses glucose for fuel $(9,35)$. Stimulation of TAL metabolic activity by saline or dDAVP treatment was associated with a local increase in GT4 mRNA, supporting the view that GT4 is involved in TAL fuel metabolism. 
Renal GT4 mRNA levels were not affected by 1 or $4 \mathrm{~d}$ of insulinopenic diabetes mellitus. Since GT4 is coexpressed with IGF-I in this segment of the nephron, and since IGF-I receptor mRNA and binding sites are also abundant in the TAL (reference 8 and our unpublished data ), we propose that IGF-I regulates local GT4 expression by autocrine or paracrine action preempting the role of circulating insulin. The combination of GT4 and IGF-I expression in this metabolically hyperactive segment of the nephron suggests the potential for local autoregulation of glucose uptake in the TAL. As a matter of speculation, such local regulatory mechanisms may be supposed to have preceded the evolution of endocrine systems of metabolic regulation.

\section{Acknowledgments}

We thank Drs. Morris Birnbaum, Graeme Bell, and Harvey Lodish for kindly providing the cDNAs used for riboprobe synthesis, Dr. Thorkil Ploug for technical advice, Dr. Peer N. Jørgenson, Novo Nordisk (Bagsvaerd, Denmark) for the GT4 antibody, and Ricardo Dreyfuss and John Ward for expert photography.

\section{References}

1. Mueckler, M. 1990. Family of glucose-transporter genes implications for glucose homeostasis and diabetes. Diabetes. 39:6-11.

2. Gould, G. W., and G. I. Bell. 1990. Facilitative glucose transporters: an expanding family. TIBS (Trends Biochem. Sci.). 15:18-23.

3. Thorens, B., M. J. Charron, and H. F. Lodish. 1990. Molecular physiology of glucose transporters. Diabetes Care. 13:219-227.

4. Kasanicki, M. A., and P. F. Pilch. 1990. Regulation of glucose transporter function. Diabetes Care. 13:219-227.

5. Rollins, B. J., E. D. Morrison, P. Usher, and J. S. Flier. 1988. Platelet-derived growth factor regulates glucose transporter expression. J. Biol. Chem. 263:16523-16526.

6. Maher, F., and L. C. Harrison. 1990. Stabilization of glucose transporter mRNA by insulin/IGF-I and glucose deprivation. Biochem. Biophys. Res. Commun. 171:210-215.

7. Masters, B. A., H. Werner, C. T. Roberts Jr., D. LeRoith, and M. K. Raizada. 1991. Developmental regulation of insulin-like growth factor-I-stimulated glucose transporter in rat brain astrocytes. Endocrinology. 128:2548-2557.

8. Chin, E., J. Zhou, and C. Bondy. 1992. Anatomical relationships in the pattern of IGF-I, IGFBP-I and IGF-I receptor gene expression in the rat kidney. Endocrinology. 130:3237-3245.

9. Silva, P. 1990. Energy and fuel substrate metabolism in the kidney. Semin. Nephrol. 10:432-444.

10. Ross, B. D., J. Espinal, and P. Silva. 1986. Glucose metabolism in renal function. Kidney Int. 29:54-67.

11. Bondy, C., H. Werner, C. T. Roberts, Jr., and D. LeRoith. 1992. Cellular pattern of type-I insulin-like growth factor gene expression during maturation of the rat brain: comparison with insulin-like growth factors I and II. Neuroscience. 46:909-923.

12. Bondy, C. A., H. Werner, C. T. Roberts, Jr., and D. LeRoith. 1990. Cellular pattern of insulin-like growth factor-I (IGF-I) and type I IGF receptor gene expression in early organogenesis: comparison with IGF-II gene expression. Mol. Endocrinol. 4:1386-1398.

13. Werner, H., M. Adamo, W. L. Lowe, Jr., C. T. Roberts, Jr., and D. LeRoith. 1989. Developmental regulation of rat brain/Hep G2 glucose transporter gene expression. Mol. Endocrinol. 3:273-279.

14. Thorens, B., H. K. Sarkar, H. R. Kaback, and H. F. Lodish. 1988. Cloning and functional expression in bacteria of a novel glucose transporter present in liver, intestine, kidney, and B-pancreatic islet cells. Cell. 55:281-290.

15. Birnbaum, M. J. 1989. Identification of a novel gene encoding an insulinresponsive glucose transporter protein. Cell. 57:305-315.

16. Nagamatsu, S., J. M. Kornhauser, C. F. Burant, S. Seino, K. E. Mayo, and G. I. Bell. 1992. Glucose transporter expression in brain. J. of Biol. Chem. 267:467-472.

17. Rand, E. B., A. M. Depaoli, N. O. Davidson, G. I. Bell, and C. F. Burant. 1992. Sequence, tissue distribution and functional characterization of the rat fructose transporter, GLUT5. Am. J. Physiol. In press.

18. Bondy, C. A., S. L. Lightman, and S. L. Lightman. 1989. Developmental and physiological regulation of aldose reductase mRNA expression in renal medulla. Mol. Endocrinol. 3:1409-1416.

19. Hsu, S. M., L. Raine, and H. Fanger. 1981. Use of avidin-biotin-peroxidase complex $(\mathrm{ABC})$ in immunoperoxidase techniques: a comparison between $\mathrm{ABC}$ and unlabeled antibody (PAP) procedures. J. Histochem. Cytochem. 29:577-580.

20. Silverman, M., and R. J. Turner. 1992. Glucose transport in the renal proximal tubule. In Handbook of Physiology, Section 8: Renal Physiology. E. Windhager, editor. Oxford University Press, New York. 2017-2038.

21. Thorens, B., H. F. Lodish, and D. Brown. 1990. Differential localization of two glucose transporter isoforms in the rat kidney. Am. J. Physiol. 259:C286C294.

22. Takata, K., T. Kasahara, M. Kasahara, O. Ezaki, and H. Hirano. 1991. Localization of $\mathrm{Na}^{+}$-dependent active type and erythrocyte/HepG2-type glucose transporters in rat kidney: immunoflourecence and immunogold study. J. Histochem. Cytochem. 39:287-298.

23. Cramer, S. C., W. M. Pardridge, and B. A. Hirayama. 1992. Colocalization of GLUT2 glucose transporter, sodium/glucose cotransporter and g-glutamyl transpeptidase in rat kidney with double-peroxidase immunocytochemistry. Diabetes. 41:766-770.

24. Guder, W. G., and F. Morel. 1992. Biochemical characterization of individual nephron segments. In Handbook of Physiology, Section 8: Renal Physiology. E. Windhager, editor. Oxford University Press, New York. 2119-2164.

25. Zorzoli, A., I. J. Turkenkopf, and V. L. Mueller. 1969. Gluconeogenesis in developing rat kidney cortex. Biochem. J. 111:181-185.

26. Kayano, T., C. F. Burant, H. Fukumoto, G. W. Gould, Y. Fan, R. L. Eddy, M. G. Byers, T. B. Shows, S. Seino, and G. I. Bell. 1990. Human facilitative transporters. J. Biol. Chem. 265:13276-13282.

27. Shepherd, P. R., E. M. Gibbs, C. Wesslau, G. W. Gould, and B. B. Kahn. 1992. Human small intestine facilitative fructose/glucose transporter (GLUT5) is also present in insulin-responsive tissues and brain. Diabetes. 41:1360-1365.

28. Burant, C. F., J. Takeda, E. Brot-Laroche, G. I. Bell, and N. O. Davidson. 1992. Fructose transporter in human spermatozoa and small intestine is GLUT5. J. Biol. Chem. 267:14523-14526.

29. Davidson, N. O., A. M. L. Hausman, C. A. If kovits, J. B. Buse, G. W. Gould, C. F. Burant, and G. I. Bell. 1992. Human intestinal glucose transporter expression and localization of GLUT5. Am. J. Physiol. 262:C795-C800.

30. Charron, M. J., F. C. Brosius III, S. E. Alper, and H. F. Lodish. 1989. A glucose transport protein expressed predominately in insulin-responsive tissues. Proc. Natl. Acad. Sci. USA. 86:2535-2539.

31. Fukumoto, H., T. Kayano, J. B. Buse, Y. Edwards, P. F. Pilch, G. I. Bell, and S. Seino. 1989. Cloning and characterization of the major insulin-responsive glucose transporter expressed in the human skeletal muscle and other insulin-responsive tissues. J. Biol. Chem. 264:7776-7779.

32. James, D. E., M. Strube, and M. Mueckler. 1989. Molecular cloning and characterization of an insulin-regulatable glucose transporter. Nature (Lond.). 338:83-87.

33. Morel, F., and A. Doucet. 1992. Functional segmentation of the nephron. In The Kidney: Physiology and Pathophysiology. D. Seldin and G. Giebisch, editor. Raven Press, Ltd., New York. 1049-1086.

34. Rajerison, R. M., D. Butlen, and S. Jard. 1976. Ontogenic development of antidiuretic hormone binding and adenylate cyclase activation. Mol. Cell. Endocrinol. 4:271-285.

35. Knepper, M. A., and F. C. Rector, Jr. 1991. Urinary concentration and dilution. In The Kidney. B. Brenner and F. Rector, Jr., editors. W. B. Saunders Company, Philadelphia. 445-482. 